\title{
Protective effect of mangiferin on doxorubicin-induced liver damage in animal model
}

\author{
Fauzul HUSNA ${ }^{1 *}(\mathbb{D})$, Wawaimuli AROZAL ${ }^{2}$ (D), Hanifah YUSUF 1 (D), Safarianti SAFARIANTI ${ }^{3}$ (D) \\ 1 Department of Pharmacology, Faculty of Medicine, Universitas Syiah Kuala, Aceh, Indonesia. \\ 2 Department of Pharmacology, Faculty of Medicine, Universitas Indonesia, Jakarta, Indonesia. \\ 3 Department of Parasitology, Faculty of Medicine, Universitas Syiah Kuala, Aceh, Indonesia. \\ * Corresponding Author. E-mail: fauzul.husna@unsyiah.ac.id (F.H.); Tel +62/852/96269898.
}

Received: 02 June 2021 / Revised: 08 October 2021 / Accepted: 13 December 2021

\begin{abstract}
Mangiferin is a bioactive compound which has antioxidant effect, but its effect on liver protection during chemotherapy with doxorubicin is understudied. The objective of this study was to assess the protective effect of mangiferin on liver injury induced by doxorubicin. The doxorubicin was injected intraperitoneally at a total dose of 15 $\mathrm{mg} / \mathrm{kg} \mathrm{b.w}$, and then the animals were orally supplemented with mangiferin (either 50 and $100 \mathrm{mg} / \mathrm{kg} \mathrm{b.w)} \mathrm{for} \mathrm{five}$ weeks. The activity of alanine aminotransferase (ALT), aspartate aminotransferase (AST), superoxide dismutase (SOD), the level of malondialdehyde (MDA) and glutathione, and liver histopathology were examined to evaluate the liver damage. The results showed that doxorubicin could cause liver cell damage to the rats. In addition, the study revealed that the supplementation of mangiferin ( 50 and $100 \mathrm{mg} / \mathrm{kg} \mathrm{b.w)} \mathrm{decreased} \mathrm{ALT} \mathrm{and} \mathrm{AST} \mathrm{activities,} \mathrm{as} \mathrm{well} \mathrm{as} \mathrm{lipid}$ peroxidation. It also increased SOD and GSH levels of liver cells $(p<0.05)$. Our study proved that the improvement in liver function and oxidative stress parameters caused by doxorubicin, indicates that the mangiferin has a protective effect against liver damage induced by doxorubicin.
\end{abstract}

KEYWORDS: Antioxidant; doxorubicin; hepatotoxicity; mangiferin; oxidative stress.

\section{INTRODUCTION}

Doxorubicin is one of the anticancer drugs in the group of anthracycline, which is still widely used in chemotherapy of solid tumors and leukemia in children and adults. However, the administration of this drug is restricted due to potential damage to other organs such as the heart, kidney, brain, and liver. This side effect is caused by one of the anticancer action mechanisms in the formating of free radicals, which cause the side effects of the doxorubicin [1].

The formation of free radicals caused by the chemical structure of the doxorubicin is done in various pathways. The quinone cluster at the tetracycline ring of doxorubicin can undergo redox cycles of quinonesemiquinone-quinone by involving some enzymes and $\mathrm{O}_{2}$ that release a number of superoxide radicals. Moreover, the metabolism of doxorubicin can also cause the formation of reactive aglycone metabolite as well as ethanol metabolite (doxorubicinol), which can disrupt the intracellular iron balance. In this case, the administration of DOX can increase the production for free radical species (or reactive oxygen species-ROS) and disturb antioxidant defence balance which initiates oxidative damage [2]. Some studies revealed evidence regarding the toxicity of doxorubicin to organs, especially the heart and kidney [3-5].

The liver, an organ that plays a significant role in metabolism, could suffer damage due to the presence of doxorubicin. Some research shows that the damage of a liver is related to the inflammation process, free radicals, oxidative stress, and lipid peroxidation which all happen simultaneously due to the administration of doxorubicin [6]. The damage to various organs, including liver, due to the administration of doxorubicin is mediated by oxidative stress. It is characterized by an increase in lipid peroxidation and changes in SOD activity in DOX-treated rats. The arrangement of mediators involved in oxidative processes can prevent doxorubicin toxicity to some tissues. Therefore, antioxidants can be used to prevent the danger and pathology actions of free radicals, including those caused by the administration of doxorubicin.

A number of active materials from plants have been proven to consist of an antioxidant effect, leading to their usage in some countries to prevent the damage caused by free radicals. The bioactive materials

How to cite this article: Husna F, Arozal W, Yusuf H, Safarianti S. Protective effect of mangiferin on doxorubicin-induced liver damage in animal model. J Res Pharm. 2022; 26(1): 44-51. 
extracted from mangoes, mangiferin, for instance, have evidence of an antioxidant effect. In Indonesia, alongside many varieties of mango, Mangifera foetida is one of the varieties with high mangiferin content. The mangiferin has been found in the trunk, fruit, root, and leaves [7]. Some research revealed that mangiferin has the effect of antitumor [8], antiviral [9], antioxidant [10], antimicrobial [11], anti-inflammatory [12], antidiabetic [13], antiatherogenic and antihyperlipidemic, and iron chelating agents [14]. Other studies also showed that the xanthone compound has strong antioxidant activity through free radical scavenger and its iron-chelating properties $[15,16]$. Therefore, this study seeks an indication of the protective effect of mangiferin on the damaged liver that is induced with DOX through the control of oxidative damage in tissues. Liver damage was evaluated by measuring the liver function parameters and liver histopathology. İn addition, oxidative damage was measured by examining lipid peroxidation markers and antioxidant properties (SOD activity and GSH level) in plasma and liver.

\section{RESULTS}

\subsection{Effect of mangiferin on liver function parameters}

This study shows that the use of doxorubicin contributes to increasing the activities of ALT and AST significantly compared to the normal rats. What is more, the supplementation of mangiferin 50 and $100 \mathrm{mg} / \mathrm{kg}$ b.w resulted in decreasing activities of ALT $(\mathrm{p}<0.05)$ and AST $(\mathrm{p}<0.05)$ significantly in the induced rats (Figure $1)$.

A

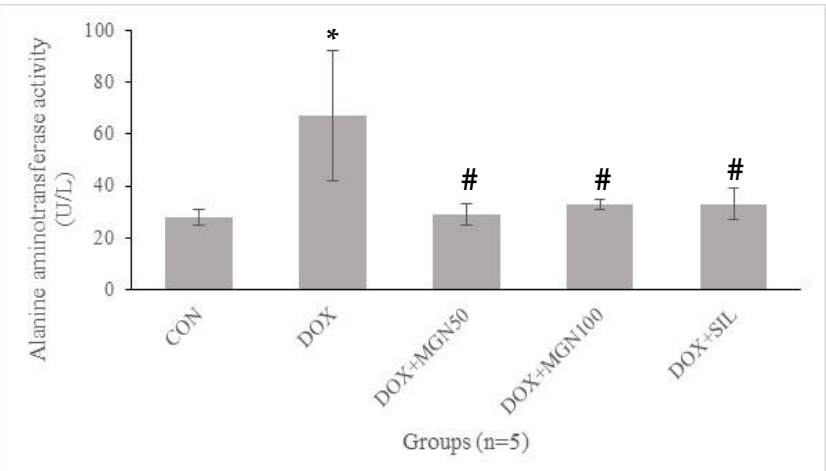

B

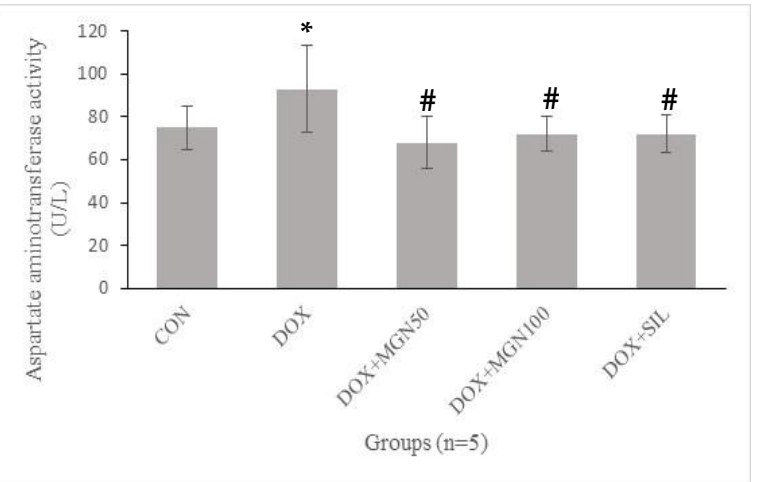

Figure 1. The effects of doxorubicin and mangiferin on liver function parameters. ALT enzyme activity (A), AST enzyme activity (B). Values are presented as mean $\pm \mathrm{SD}\left(\mathrm{n}=5\right.$ for each group). ${ }^{*} p<0.05$ vs. CON group. \# $p<0.05$ vs DOX group.

\subsection{Effect of mangiferin on oxidative stress parameters}

Figure 2 shows the effect of doxorubicin and mangiferin on GSH levels (A) and SOD activity (B) in the liver's rat and MDA level (C) in the plasma and liver. Upon the administration of doxorubicin, the GSH level in liver markedly decreased that is $2.70 \pm 0.63$ vs. $6.67 \pm 1.72(\mathrm{p}<0.01)$. The reduction of SOD activity in the liver also happened in rats treated by DOX compared to the normal rats $(130.45 \pm 14.3$ vs. $150.25 \pm 7.61$, $p<$ 0.05). Our data showed that the MDA level in the liver is higher than the MDA level in the plasma. Similarly, the MDA level increased significantly, both in plasma and liver tissue compared to the normal groups (plasma $0.28 \pm 0.04$ vs. $0.19 \pm 0.02, p<0.01$ and liver $1.48 \pm 0.22$ vs. $0.96 \pm 0.16, p<0.01$ ). The administration of mangiferin 50 and $100 \mathrm{mg} / \mathrm{kg}$ b.w has led to increasing GSH levels $(\mathrm{p}<0.01)$ and SOD activity $(\mathrm{p}<0.05)$ in the induced rats. Notably, mangiferin did not significantly differ at the low and high doses in change the GSH and SOD activity. The supplementation of all doses of mangiferin dropped the MDA level significantly $(\mathrm{p}<0.05$ and $\mathrm{p}<0.01$ in the liver). Interestingly, mangiferin $100 \mathrm{mg} / \mathrm{kg}$ b.w was superior to mangiferin $50 \mathrm{mg} / \mathrm{kg}$ b.w in repaired lipid peroxidation levels in the liver of induced rats.

\subsection{Effect of mangiferin on histopathology of liver}

This research has found various damages on liver cell structure, including necrosis, degradation, sinusoidal dilatation, polymorphonuclear and mononuclear infiltration, and Kupffer cell proliferation at the induced rats. The damage does not happen at all in induced rats. Two of five induced rats indicated normal liver histopathology (Figure 3). The damages, however, are found in the rates that have been applied MNG 50 
dan MGN 100. Although it looks lighter, we did not score because of the very large variety of liver histopathology findings. Figure 3 shows the liver histopathology qualitatively in which represents the liver description of this study.

A

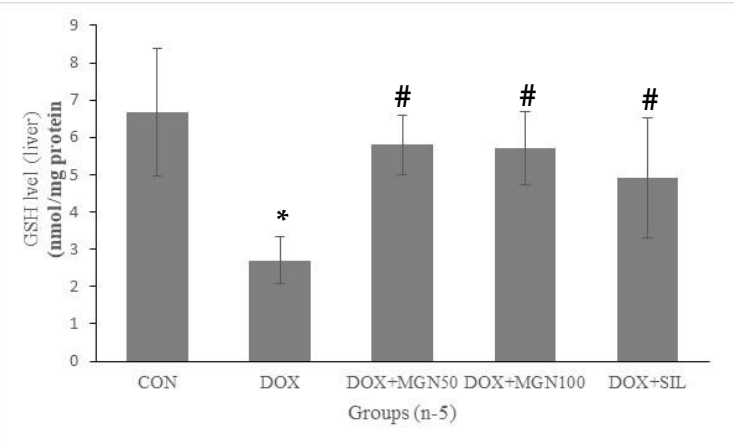

B

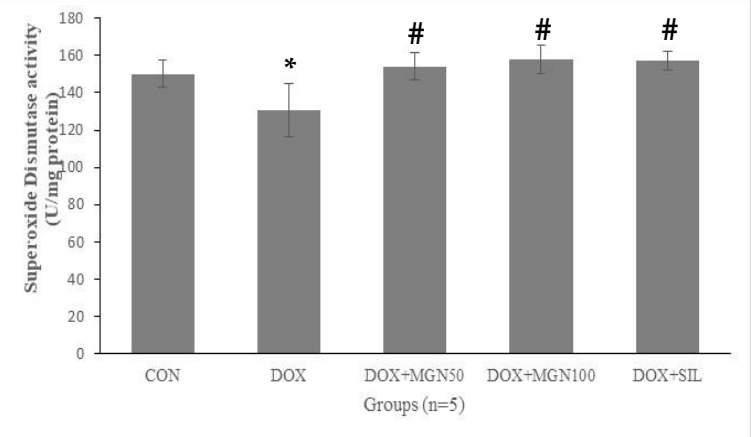

C

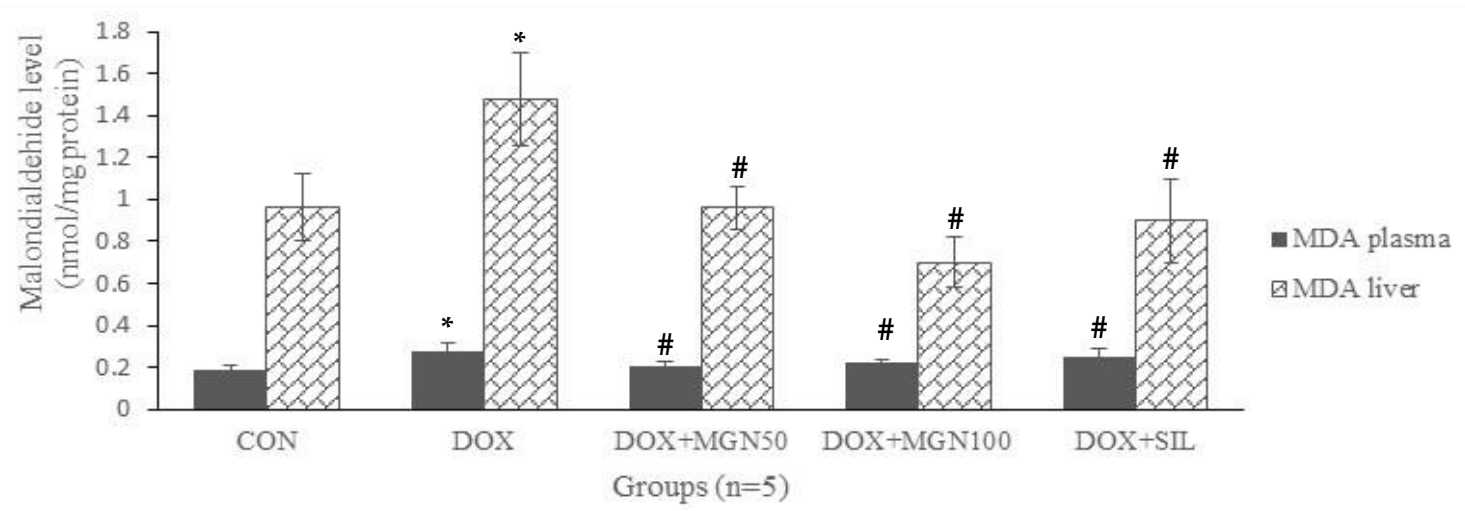

Figure 2. The effects of doxorubicin and mangiferin on oxidative stress markers. GSH level (A), SOD activity (B), MDA level (C) in plasma and liver rats. Values are presented as mean $\pm \mathrm{SD}$ ( $\mathrm{n}=5$ for each group). ${ }^{*} p<$ 0.05 vs. CON group. $\# p<0.05$ vs DOX group.

\section{DISCUSSION}

This research analyzed the damage on liver cells caused by the administration of doxorubicin as well as examines the effect of the administration of mangiferin in protecting hepatocyte damage. One of the action mechanisms of doxorubicin is to produce ROS. This mechanism was initiated by the anticancer effect and side effects of the doxorubicin. In addition, the administration of the doxorubicin can decrease the defence of the endogenous antioxidant, so that oxidative stress occurs. Silymarin is a flavonoid which has an antioxidant effect, and it has been proven to reduce the toxicity of doxorubicin in some organs. This concern has motivated us to use silymarin as a positive control in this research [17].

The findings of the research show that the usage of doxorubicin increased the activity of ALT and AST. The damage of liver cells, regardless of its cause, could contribute to the release of enzymes in the cytoplasm or mitochondria from cells to blood circulation. The ALT enzyme is located primarily on the liver cell cytosol In contrast, the AST enzyme can be found in liver cells including cells in other organs, notably the heart, kidney, and pancreas. The increased activities in such enzymes are considered as a symptom of the damage to liver cells. In the case of acute liver damages, the ALT escalates more significantly than the AST [18]. This result shows that the injection of doxorubicin damages liver cells, corresponding to the results of other studies $[6,19]$.

The doxorubicin is used as an anticancer to counteract the growth of abnormal cancer cells. Nonetheless, the action mechanism of the doxorubicin in damaging the cells was through destructing DNA so that the cell becomes apoptosis [2]. In dealing with this situation, the administration of mangiferin 50 and $100 \mathrm{mg} / \mathrm{kg} \mathrm{b.w}$ in the rats has maintained the activities of ALT and AST levels close to the activities of enzymes as in a normal group. This is due to the ability of the mangiferin in increasing the endogenous antioxidant defence 
mechanisms through nuclear erythroid-2 related factor-2 (Nrf2) and decreased inflammation by inhibiting NF$\kappa \mathrm{B}$. The transcription factor of Nrf2 controlled antioxidant protein-coding genes such as GSH and phase II metabolic enzymes like NQ01 and GST. Oxidative stress causes Nrf2 in the cytosol to translocate to the nucleus, binding with the antioxidant response element (ARE). This condition will lead to an increase in the antioxidant enzyme transcription and decrease its sensitivity to oxidative damage in which will cause the cytoprotection effect [20,21].
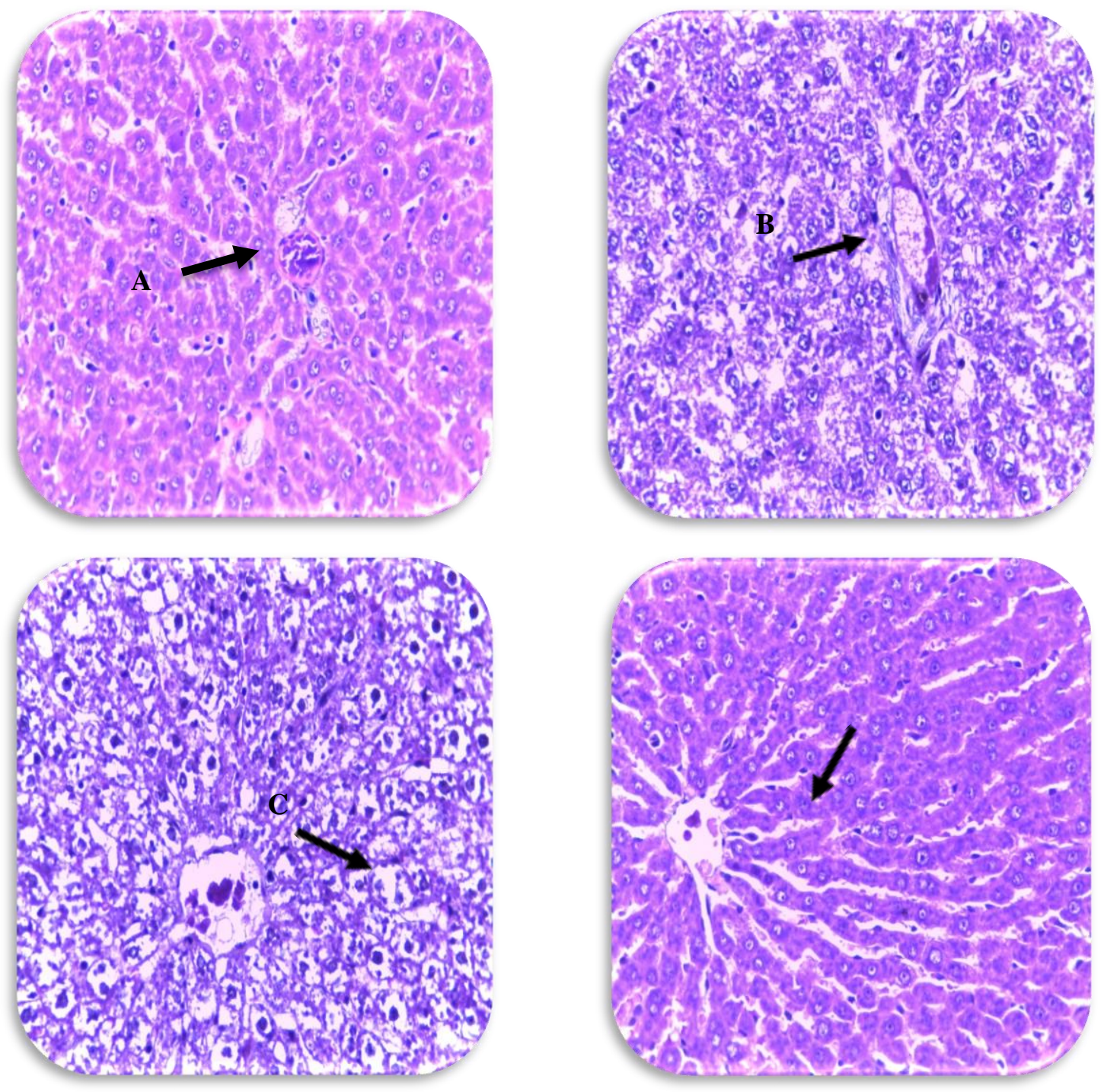

Figure 3. The effects of doxorubicin and mangiferin on liver histopathology overview. A. Necrosis, Midzonal degradation, C. Cytoplasmic vacuolization, and D. Normal.

The administration of doxorubicin in this research has also significantly decreased the activities of superoxide dismutase (SOD) in the liver. This result is in line with the findings of other studies [6,22]. Similarly, the usage of doxorubicin can decrease protein content and cytosolic SOD enzyme activities by oxidating active sites or forming cross-link protein [3]. Likewise, enzymatic defence is a process where the SOD plays an essential role in the defence of antioxidants in the very front line in the body. In this case, the SOD acts as the catalyst in $\mathrm{O}_{2}{ }^{-}$- dismutation reaction and forms $\mathrm{H}_{2} \mathrm{O}_{2}$ which are later changed into water and $\mathrm{O}_{2}$ through other enzymatic reactions. The accumulation of ROS, accompanied by a decrease in antioxidant defence activities, will cause oxidative stress [20,23].

The decline in SOD activities shows that doxorubicin injection will disrupt the equilibrium of endogenous antioxidant defence. However, it was unsure whether the decrease in SOD activities was associated with a dropped endogen antioxidant or due to the accumulation of ROS, which made the activities of SOD reach its saturation level. To figure out the cause, SOD activities should be examined serially. 
In addition, this research reveals that the administration of doxorubicin reduced GSH content in the liver of induced rats more significantly than the normal group. The lower level of GSH is considered as a sign of cellular oxidative stress due to the activities of the hydrosulfide glutathione group involving in antioxidant and detoxification reactions [20]. GSH is the combination of three amino acids, glutamate, cysteine, glycine, which have free thiol groups and are found in animal cells in high concentrations. GSH is an intracellular antioxidant in the second line, which prevents the formation of intracellular ROS and lipid peroxidation. The direct role of GSH antioxidants is to maintain the equilibrium of thiol-disulfide, which is related to cellular redox potential. The drop in GSH disrupts the thiol redox status and changes the equilibrium of cellular physiology between prooxidants and antioxidants [20,23]. What is more, GSH is a cofactor of the glutathione peroxidase (GPx) enzyme, which is used to eliminate $\mathrm{H}_{2} \mathrm{O}_{2}$ by using $\mathrm{H}_{2} \mathrm{O}_{2}$ to oxidate GSH into GSSG. Correspondingly, the decline of GSH decreases its ability to eliminating $\mathrm{H}_{2} \mathrm{O}_{2}$ so that $\mathrm{H}_{2} \mathrm{O}_{2}$ can react with free iron to form $\mathrm{OH}^{*}$ and initiate cellular component peroxidation [24].

Lipid peroxidations are an important symptom of tissue damage by oxidative stress. Lipid peroxidation is defined as a peroxidase process of polyunsaturated fatty acids (PUFA) in the biological membrane. This process is initiated by hydroxyl radical which abstracts one hydrogen atom from methylene group in PUFA membrane phospholipids so that polar lipid hydroperoxides are formed. An example of oxidated products is epoxide and aldehyde (HNE and MDA). The examination of lipid peroxide in vivo can indirectly be done through the measurement of MDA content [20].

In line with some findings in previous research [6, 21,22], this study found a significant increase in the MDA level of induced rats both in plasma and liver tissue. The rise in MDA content proved that the administration of doxorubicin could result in oxidative stress. This was linked closely with the doxorubicin's chemical structure, notably the tetracycline ring which contains the hydroquinone-quinone group. Quinone is one of the groups which can receive electrons. The addition of one electron into a quinone group in tetracycline ring- $\mathrm{C}$ can form semiquinone in which can reduct oxygen swiftly, leading to the formation of quinone and $\mathrm{O}_{2}{ }^{\circ}$. The higher the doxorubicin content is the more $\mathrm{O}_{2}{ }^{*}$-increases [3]. The $\mathrm{O}_{2}{ }^{*}$ - radical can penetrate to transporting channels of ferritin. It also has a lower redox potential than ferric ion in the ferritin core. The combination of these two factors contributes to the extraction of iron from ferritin core so the release of iron in the form of $\mathrm{Fe}^{2+}$ occurs. Doxorubicin semiquinone can release the iron-bound on ferritin with an unknown mechanism [3]. The doxorubicin is also reactive against cytoplasmic aconitase. The reactivity of doxorubicinol causes an increase in free iron content $[3,25]$.

The supplementation of mangiferin 50 and $100 \mathrm{mg} / \mathrm{kg}$ b.w significantly decreased the MDA content in the liver and plasma compared to the DOX group. The ability of mangiferin in lessening lipid peroxidase can be associated with its antioxidant activities. Mangiferin had the activity of scavenging free radicals. Many research has also shown that mangiferin has high activities in scavenging free radicals, such as $\mathrm{DPPH}, \mathrm{O}_{2}^{\circ}{ }^{\circ}$, $\mathrm{NO},{ }^{\circ} \mathrm{OH}-$ or galvinoxyl [12]. In addition, the effect of mangiferin antioxidant is caused by its properties as $\mathrm{Fe}^{3+}$ chelator, which can induce $\mathrm{Fe}^{2+}$ oxidation, not merely because of its scavenger property. Similarly, the mangiferin leads $\mathrm{Fe}^{2+}$ to undergo swift oxidation and prevents $\mathrm{Fe}^{3+}$ reduction by ascorbate so that it can limit the availability of iron ions to be involved in Fenton and Haber-Weiss reaction. In the end, lipid peroxidase can be restricted [15]. This study also found that the administration of mangiferin increase SOD activities as well as escalate GSH content in the liver up to the same level of the control group. The rise in GSH content in this research indicated that mangiferin could potentially protect hepatocytes from oxidative damage induced by doxorubicin. The repair between low and high mangiferin doses was not significantly different.

Several previous studies related to this research reported that the liver damage was due to the injection of doxorubicin through a histopathology examination. The damages in liver cells can be in the form of necrosis, atypia, inflammation, degeneration, pleomorphism of hepatocyte, ductus proliferation, cytoplasmic eosinophilia, parenchymal necrosis, and inflammation cells around the portal area [22]. In this research, we conducted a histopathology examination to check liver damage due to the administration of doxorubicin and mangiferin. The liver cell damages associated with the administration of doxorubicin ranged from Kupffer cell inflammation, polymorphonuclear and mononuclear infiltration, sinusoidal dilatation, degeneration, and cytoplasmic granulation, and necrosis. However, the damages are not consistent in all animals in the DOX group.

In the DOX+MGN group, we also found cell damages as in the DOX group. Despite not all animals in this group showed this abnormal situation. From this observation, it is difficult to conclude the effect of mangiferin on the damaged hepatocytes due to variation in the results of liver histopathology. Although the histopathology overview of liver tissue gained in this research was similar to some previous research studies 
[26,27], it is inconclusive for the effects of doxorubicin and mangiferin toward liver cell damage at the histopathology. This is in line with other studies stating that the administration of antioxidants did not protect liver cells from damages due to the administration of doxorubicin at the histopathology level [26]. The administration of mangiferin presented repair in histopathology of the liver cell only in some cases. However, worse damage to liver cells was also found in other cases.

\section{CONCLUSION}

This research concludes that doxorubicin-induced oxidative damage to the liver cell. Likewise, the administration of mangiferin of $50 \mathrm{mg} / \mathrm{kg} \mathrm{b.w}$ and $100 \mathrm{mg} / \mathrm{kg}$ b.w can prevent the liver cell of the rats from oxidative damage.

\section{MATERIALS AND METHODS}

\subsection{Chemicals and animal}

The doxorubicin was purchased from Combiphar (Indonesia), and mangiferin 99\%, along with silymarin 90\% (SIL), was purchased from Plamed Science Technology (Xian, China). Bradford reagent, BSA, dl-epinephrine, thiobarbituric acid, standard MDA (TMEP), standard GSH, and DTNB were obtained from Sigma-Aldrich (USA). Enzymatic kits to determine the aspartate transaminase (AST) dan alanine transaminase (ALT) activities were obtained from Diasys (Germany). Other reagents were obtained from Merck (USA).

This research used plasma and liver tissues from 25 male Sprague-Dawley rats, 12-16 weeks of age, with 150-200 grams body weight. The rats were derived from Bogor Agricultural Institute (IPB University), and they had been induced with doxorubicin. All rats were housed in the standard laboratory with temperature $23 \pm 2^{\circ} \mathrm{C}, 35-60 \%$ humidity, and the light-dark cycle of $12 \mathrm{~h}$ during the experiment. This study was approved by the Ethics Committee of the Faculty of Medicine, University of Indonesia (No. 475/PT02.FK/ETIK/2012).

\subsection{Experimental design}

The rats were assigned randomly into five groups of five rats and received the treatment for five weeks. The dose and the procedure treatment according to previous study [28].

The detailed treatment for the group of rats is described as follows:

- The normal group was given corn oil and $\mathrm{NaCl} 0.9 \%$ (intraperitoneal with the schedule based on the injection of doxorubicin).

- The DOX group was dosed doxorubicin $2.5 \mathrm{mg} / \mathrm{kg}$ b.w every 48 hours for two weeks (cumulative dose of $15 \mathrm{mg} / \mathrm{kg} \mathrm{b.w)}$.

- The DOX+MGN $50 \mathrm{mg} / \mathrm{kg}$ b.w group was applied doxorubicin for two weeks with additional mangiferin $50 \mathrm{mg} / \mathrm{kg}$ b.w which was extended to five weeks.

- The DOX+MGN $100 \mathrm{mg} / \mathrm{kg}$ b.w group received similar treatment to the DOX+MGN $50 \mathrm{mg} / \mathrm{kg}$ b.w group, except that the dose was $100 \mathrm{mg} / \mathrm{kg}$ b.w.

- The positive control group was given DOX for two weeks with the addition of Silymarin (SIL) 50 $\mathrm{mg} / \mathrm{kg}$ b.w for five weeks.

Doxorubicin was administered intraperitoneally, while mangiferin and silymarin were given orally. Determination of mangiferin dosage based on previous studies with modifications [29]. After five weeks, all rats were sacrificed by cervical decapitation. The blood was collected using tubes coated EDTA. The plasma was used to estimate MDA level, AST and ALT activity. The liver tissue was excised and rinsed in ice-cold normal saline, then homogenized with a teflon homogenizer at $4^{\circ} \mathrm{C}$ in normal saline

The plasma and liver homogenate were used to calculate malondialdehyde level by the method TBAWills [30], the activity of SOD by the Misra dan Fridovichs method [31], and the reduced glutathione (GSH) was estimated using Ellman's method [32].

\subsection{Liver histopathological study}

To begin with, a portion of the liver tissue was rinsed with normal saline then fixed in $10 \%$ buffered formalin phosphate. A piece of liver was embedded in paraffin and cut into five $\mu \mathrm{m}$ - thick, and stained with hematoxylin and eosin. Assessing the histopathology of the liver used a routine procedure, and it was examined under the microscope's light. The alterations that relate to histopathological changes were examined qualitatively by a certified pathologist. 


\subsection{Statistical analysis}

All data were expressed as mean \pm standard deviation (SD). The statistical analysis was carried out by one-way ANOVA followed by LSD using the software. The values of $p<0.05$ were considered statistically significant.

Acknowledgements: The authors thank Chiswyta Chaliana, Sri Rahayu, Edwina R Monayo dan R. Aulia from the Pharmacology Departement, Universitas Indonesia, Indonesia for their technical assistance and support during this research.

Author contributions: Concept - F.H., W.A.; Design - F.H., W.A., H.Y.; Supervision - F.H., W.A.; Resources - F.H., W.A., HY; Materials - F.H., W.A., SS.; Data Collection and/or Processing - F.H., S.S.; Analysis and/or Interpretation F.H., W.A.; Literature Search - F.H., W.A., S.S.Writing -F.H.; Critical Reviews - F.H., H.Y,. S.S.

Conflict of interest statement: The authors declared no conflict of interest.

Ethics committee approval: This study was approved by the Ethics Committee of the Faculty of Medicine, University of Indonesia (No. 475/PT02.FK/ETIK/2012).

\section{REFERENCES}

[1] Chabner BA, Bertino J, Cleary J, Ortiz T, Lane A, Supko JG, Ryan D. Cytotoxic agent. In: Brunton LL, Chabner BA, Knollmann BC, editors. Goodman \& Gilman's The Pharmacological Basic of Therapeutics. 12th ed. McGraw-Hill, United Stated, 2011, pp.1712-1715.

[2] Wenningmann N, Knapp M, Ande A, Vaidya TR, Ait-Oudhia S. Insights into doxorubicin-induced cardiotoxicity: Molecular mechanisms, preventive strategies, and early monitoring. Mol Pharmacol. 2019; 96: 219-32. [CrossRef]

[3] Molehin OR, Adeyanju AA, Adefegha SA, Oyeyemi AO, Idowu KA. Protective mechanisms of protocatechuic acid against doxorubicin-induced nephrotoxicity in rat model. J Basic Clin Physiol Pharmacol. 2019; 30(4). [CrossRef]

[4] Arozal W, Sari FR, Watanabe K, Arumugam S, Veeraveedu PT, Ma M, Thandavarayan RA, Sakumaran V, Lakshmanan AP, Kobayashi Y, Mito S, Soetikno V, Suzuki K. Carvedilol-afforded protection against daunorubisininduced cardiomyopathic rats in vivo: effect on cardiac fibrosis dan hypertrophy. ISRN Pharmacol. 2011; 14: 1-8. Article ID 430549. [CrossRef]

[5] Tacar O, Sriamornsak P, Dass CR. Doxorubicin: An update on anticancer molecular action, toxicity and novel drug delivery systems. J Pharm Pharmacol. 2012; 65: 157-70. [CrossRef]

[6] Molehin OR, Idowu KA, Olaoye AB, Fakayode AE, Adesua OO. Influence of Clerodendrum volubile leaf extract on doxorubicin-induced toxicity and inhibition of carbonyl reductase mediated metabolism. J. Complement. Integr. 2021: 5. [CrossRef]

[7] Shah KA, Patel MB, Patel RJ, Parmar PK. Mangifera indica (mango). Pharmacog Rev. 2010; 4(7): 42-48. [CrossRef]

[8] Guha S, Ghosal S, Chattopadhyay U. Antitumor, immunomodulatory and anti-HIV effect of mangiferin, a naturally occurring glucosylxanthone. Chemotherapy. 1996; 42: 443-451. [CrossRef]

[9] Yoosook C, Bunyapraphatsara N, Boonyakiat Y, Kantasuk C. Anti-herpes simplex virus activities of crude water extracts of Thai medicinal plants. Phytomedicine. 2000; 6: 411-419. [CrossRef]

[10] Muruganandan S, Gupta S, Kataria M, Lal J, Gupta PK. Mangiferin protect the streptozotocin-induced oxidative damage to cardiac and renal tissue in rats. Toxicol. 2002; 176: 165-173. [CrossRef]

[11] Shabani Z, Sayadi A. The antimicrobial in vitro effects of different concentrations of some plant extracts including tamarisk, march, acetone and mango kernel. J App Pharm Sci. 2014; 4(5): 75-79. [CrossRef]

[12] Leiro JM, Alvarez E, Arranz JA, Siso IG, Orallo F. In vitro effects of mangiferin on superoxide concentrations and expression of the inducible nitric oxide synthase, tumor necrosis factor- $\alpha$ and transforming growth factor- $\beta$ genes. Biochem Pharmacol. 2003; 65(8): 1361-1371. [CrossRef]

[13] Aderibigbe AO, Emudianughe TS, Lawal BA. Evaluation of antidiabetic action of mangifera indica in mice. Phytother Res. 2001; 15(5): 456-458. [CrossRef]

[14] Hossain MS, Ahmed M, Islam A. Hypolipidemic and hepatoprotective effect of different fraction of ethanolic extract of immature leave of Mangifera indica (Linn) in alloxan induced diabetic rats. IJPSR. 2010; 1(11): 132-138. [CrossRef]

[15] Pardo-Andreu G, Delgado R, Núñez-Sellés AJ, Vercesi AE. Dual mechanism of mangiferin protection against ironinduced damage to 2-deoxyribose and ascorbate oxidation. Pharmacol Res. 2006; 53(3): 253-260. [CrossRef] 
[16] Purwaningsih EH, Hanani E, Wahidiyat PA, Krisnamurti DGB. The chelating effect of mangifera foetida water extract on serum thalassemic patients. J Indon Med Assoc. 2011; 61(8): 321-325.

[17] Cecen E, Dost T, Culhaci N, Karul A, Ergur B, Birincioglu M. Protective effect of silymarin against doxorubicininduced toxicity. Asian Pacific J cancer Prev. 2011; 12(10): 2697-2704. [CrossRef]

[18] Ozer J, Ratner M, Shaw M, Bailey W, Schomaker S. The current state of serum biomarkers of hepatotoxicity. Toxicol. 2008; 245(3): 194-205. [CrossRef]

[19] Firat O, Kirdox O, Makay O, Caliskan C, Yilmaz F, Ilgezdi S, Karabulut B, Coker A, Zeytunlu M. Can hyperbaric oxygenation decrease doxorubicin hepatotoxicity and improve regeneration in the injured liver? J Hepatobiliary Pancreat Surg. 2009; 16(3): 346-352. [CrossRef]

[20] Halliwell B, Gutteridge JMC. Free Radicals in Biology and Medicine, 3rd ed, Oxford Univ Press, New York, 2007.

[21] Pal PB, Sinha K, Sil PC. Mangiferin, a natural xanthone, protects murine liver in $\mathrm{Pb}(\mathrm{II})$ induced hepatic damage and cell death via MAP Kinase, NF-B and mitochondria dependent pathway. Plos one. 2013; 8(2): 1-17. [CrossRef]

[22] Yagmurca M, Bas O, Mollaoglu H, Sahin O, Nacar A, Karaman O, Songur A. Protective effect of erdostein on doxorubicin-induced hepatotoxicity in rats. Arch Med Res. 2007; 38(4): 380-385. [CrossRef]

[23] Valko M, Rhodes CJ, Moncol J, Izakovic M, Mazur M. Free radicals, metals, and antioxidants in oxidative stressinduced cancer. Chem Biol Interact. 2006; 160(1): 1-40. [CrossRef]

[24] Mirończuk-Chodakowska I, Witkowska AM, Zujko ME. Endogenous non-enzymatic antioxidants in the human body. Adv Med Sci. 2018; 63(1): 68-78. [CrossRef]

[25] Liu X, Qiu Y, Liu Y, Huang N, Hua C, Wang Q, et al. Citronellal ameliorates doxorubicin-induced hepatotoxicity via antioxidative stress, antiapoptosis, and proangiogenesis in rats. J Biochem Mol Toxicol. 2021; 35(2): e22639. [CrossRef]

[26] Injac R, Perse M, Obermajer N, Djordjevic-Milic V, Prijatelj M, Djordjevic A, et al. Potential hepatoprotective effect of fullerenol $\mathrm{C}_{60}(\mathrm{OH})_{24}$ in doxorubisin-induced hepatotoxicity in rats with mammary carcinoma. Biomaterials. 2008; 29: 3451-60.

[27] Kalender Y, Yel M, Kalender S. Doxorubicin hepatotoxicity and hepatic free radical metabolism in rats: the effect of vitamin E and catechin. Toxicol. 2005; 209: 39-45. [CrossRef]

[28] Arozal W, Suyatna FD, Juniantito V, Rosdiana DS, Amurugam S, Aulia R, et al. The effects of mangiferin (Mangifera indica L) in doxorubicin-induced cardiotoxicity in rats. Drug Res. 2014; 65(11): 574-580. [CrossRef]

[29] Fajri P, Estuningtyas A, Louisa M, Freisleben HJ. The preventive effect of Mangifera foetida L. leaf extract administered simultaneously to excess iron on markers of iron overload in Spraque-Dawley rats. Med. J. Indones. 2017; 26(4): 246-252. [CrossRef]

[30] Uchiyama M, Mihara M. Determination of malonaldehyde precursor in tissues by thiobarbituric acid test. Anal Biochem. 1978; 86(1): 271-278. [CrossRef]

[31] McCord JM, Fridovich I. The reduction of cytochrome c by milk xanthine oxidase. J Biol Chem. 1968; 243(21): 57535760. [CrossRef]

[32] Ellman GL. Tissue sulfhydryl groups. Arch Biochem Biophys. 1959; 82(1): 70-77. [CrossRef]

This is an open access article which is publicly available on our journal's website under Institutional Repository at http://dspace.marmara.edu.tr. 